\title{
Aplikasi 3d Vr Class Sebagai Inovasi Media Pembelajaran Ditengah Pandemik
}

\author{
Yoyon Efendi ${ }^{1}$, Rometdo Muzawi ${ }^{2}$, Unang Rio $^{3}$, Lusiana ${ }^{4}$ \\ ${ }^{1}$ Program Studi Teknologi Informasi, STMIK Amik Riau \\ ${ }^{2,3}$ Program Studi Manajemen Informatika, STMIK Amik Riau \\ ${ }^{4}$ Program Studi Teknik Informatika, STMIK Amik Riau \\ yoyonefendi@stmik-amik-riau.ac.id,rometdomuzawi@stmik-amik-riau.ac.id, \\ unangrio@stmik-amik-riau.ac.id, lusiana@stmik-amik-riau.ac.id
}

\begin{abstract}
Abstrak
Pada saat pandemik ini diperlukan inovasi dalam pembelajaran secara daring. Untuk mengatasi kebosanan karena sudah memasuki 3 semester dengan menggunakan media online. Dosen dituntut untuk dapat memberikan inovasi dengan teknologi dalam media pembelajarannya. Salah satunya teknologi Virtual Reality yang dapat diterapkan di kelas dengan berbasis 3D. mata kuliah yang dipakai pada VR class ini yaitu Internet of things. Aplikasi 3D VR Class menggunakan smartphone berbasis android dan tambahan alat bantu VR Box. Aplikasi ini telah digunakan oleh 16 mahasiswa di STMIK Amik Riau dengan hasil baik. Dengan adanya aplikasi ini membantu dosen dalam meningkatkan kualitas pembelajaran ditengah merosotnya minat siswa dalam pembelajaran secara daring.
\end{abstract}

Kata kunci: 3D, Virtual Reality, Pandemik, STMIK Amik Riau

\section{Abstract}

During this pandemic, innovation in online learning is needed. To overcome boredom because it has entered 3 semesters by using online media. Lecturers are required to be able to provide innovation with technology in their learning media. One of them is Virtual Reality technology that can be applied in 3D-based classrooms. The course used in this VR class is the Internet of things. The 3D VR Class application uses an Android-based smartphone and additional VR Box tools. This application has been used by 16 students at STMIK Amik Riau with good results. With this application, it helps lecturers to improve the quality of learning in the midst of declining student interest in online learning.

Keywords: 3D, Virtual Reality, Pandemic, STMIK Amik Riau

\section{Pendahuluan}

Pada pembelajaran dikampus diperlukan inovasi untuk menarik minat mahasiswa agar tidak terjadi kebosanan. Apalagi ditengah pandemic, dosen hanya melakukan kuliah daring menggunakan gmeet dan classroom.

Selain itu dengan mahasiswa dirumah tidak terjadi penurunan antuasis belajar mahasiswa. dengan memasuki masa pandemic selama 3 semester ini akan memberikan dampak tidak baik.
Mulai dari dampak psikologis mahasiswa sampai pada perekonomian orang tua.

Diperlukan teknologi yang dapat meningkatkan kreatifitas dosen dalam membuat media pembelajaran yang interaktif dan menarik.

Salah satu media pembelajaran yang menjadi trend yaitu Virtual Reality. virtual reality (VR) merupakan simulasi gambar atau seluruh lingkungan yang dihasilkan komputer yang dapat dialami 
menggunakan peralatan elektronik khusus, yang memungkinkan penggunanya "hadir" di lingkungan alternatif seperti di dunia nyata terhadap objek dan informasi virtual tiga dimensi (3D) dengan data tambahan seperti grafik atau suara(Jamil, 2018).

Saat ini format 3D, salah satu hal yang baru bagi masyarakat. Karena pada umumnya lebih bersifat 2 dimensi (2D). sensasi 3D mendukung psikologi pengguna untuk dapat merasakan suasana dengan fitur kondisi asli. Sistem koordinat 3D pada VR menganut sistem koordinat kartesian, hal ini dikarenakan pengguna dapat melihat obyek dalam dunia maya dalam segala penjuru mulai dari atas, bawah, kiri, kanan, belakang ataupun depan (Sulistyowati, 2017).

\section{Tinjauan Literatur}

Tinjauan literatur berisi teori dan konsep yang berkaitan erat dengan masalah dalam penelitian, seperti teori mengenai 3 Dimensi, Virtual Reality, media Pembelajaran, android dan VR box.

\section{Dimensi}

3 Dimensi (3D) adalah media menurut bentuk dan ciri fisik yang memiliki ukuran panjang, lebar, dan tebal serta dapat diamati dari berbagai arah pandang mana saja(Arifudin et al., 2019).

3D merupakan suatu bentuk perubahan visual dari lingkungan virtual 3 dimensi yang dikalkulasikan dari 3 sumbu $(\mathrm{X}, \mathrm{Y}, \mathrm{Z})$.

\section{Virtual Reality}

Virtual Reality merupakan sebuah teknologi yang memungkinkan seseorang melakukan sebuah simulasi terhadap objek nyata dengan menggunakan komputer yang akan membuat suasana
3D sehingga membuat pemakai seolah terlibat secara fisik.

Dari segi pengertian Virtual Reality adalah teknologi berbasiskan komputer yang mengkombinasikan perangkat khusus input dan output agar pengguna dapat berinteraksi secara mendalam dengan lingkungan maya seolah-olah berada pada dunia nyata (Yoyon Efendi, 2018).

Teknologi VR telah banyak diterapkan di beberapa sektor seperti pendidikan, hiburan, kedokteran, penerbangan, arsitek, militer, dan lain sebagainya(Jamil, 2018).

Beberapa peranan VR seperti pembelajaran interaktif, simulasi, promosi dan permainan kini semakin banyak dikembangkan(Saurik et al., 2019)

\section{Media Pembelajaran}

Peranan media pembelajaran dalam proses belajar dan mengajarmerupakan satu kesatuanyang tidak dapat dipisahkan daridunia pendidikan. Media pembelajaran merupakan segala sesuatu yang dapat digunakan untuk menyalurkan pesan pengirim kepada penerima, sehingga dapat merangsang pikiran, perasaan, perhatian, dan minat peserta didik untuk belajar (Tafonao, 2018).

Salah satu faktor penyesuaian yang berkaitan dengan pengajaran adalah media pembelajaran yang perlu dipelajari dan dikuasai oleh dosen sehingga mereka dapat menyampaikan materi kuliah kepada para peserta didik secara baik, berdaya guna, dan berhasil guna(Wahid, 2018).

\section{Android}

Android adalah sistem operasi untuk telepon seluler yang berbasis Linux. Android utamanya adalah produk Google, tetapi lebih tepatnya 
bagian dari Open Handset Alliance (Efendi \& Junaidi, 2018). Android menyediakan platform terbuka bagi para pengembang untuk membuat aplikasi mereka sendiri(Gumuda, 2011). Android memiliki beberapa versi mulai dari versi alfa, beta sampai sekarang terbaru versi 11.

\section{VR Box}

VR box merupakan alat pengujian untuk aplikasi mobile berbasi Virtual Reality. alat bantu VR Box atau Lensa VR lainnya sehingga dapat membuat objek 3 dimensi dapat dilihat menyerupai aslinya(Saurik et al., 2019).

\section{Kerangka Kerja Penelitian}

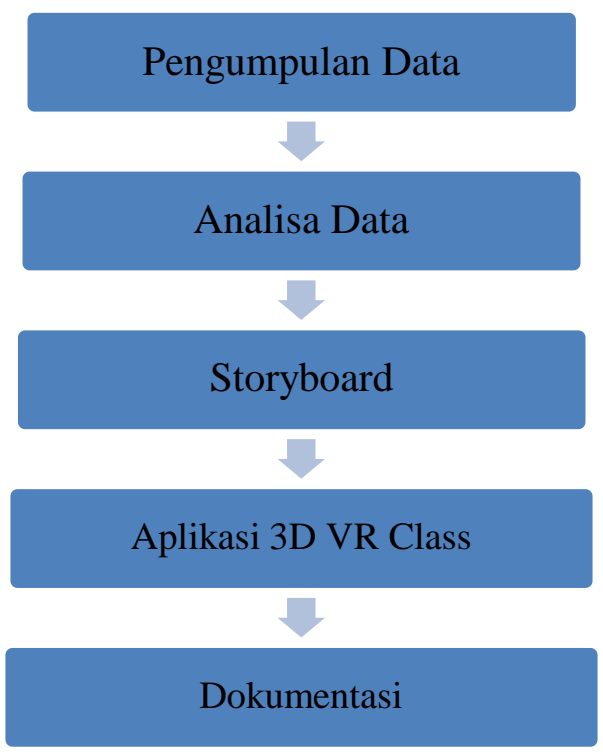

Gambar 1. Kerangka kerja Penelitian

Uraian gambar 1 kerangka kerja penelitian sebagai berikut:

1. Pengumpulan Data, melalui tinjauan pustaka dari jurnal dan buku, wawancara dan survei langsung pembelajaran STMIK Amik Riau khususnya mata kuliah Internet of things.

2. Analisa Data untuk mempersiapkan storyboard.
3. Perancangan Storyboard, setelah data dan analisa dilanjutkan storyboard berisi author, background, materi dan video

4. Aplikasi 3D VR, untuk mengetahui tampilan dan testing aplikasi menggunakan VR Box.

5. Dokumentasi, tahap ini dilakukan setelah dilakukan testing dan evaluasi untuk memudahkan pengguna dalam menjalankan aplikasi ini.

\section{Hasil dan Pembahasan}

Hasil dari aplikasi 3D VR Class dapat dililhat pada smartphone berbasis android dengan cara menginstall Millealab viewer pada playstore. Dengan account gmail yang sudah didaftarkan terlebih dahulu. Dapat dilihat pada gambar berikut:

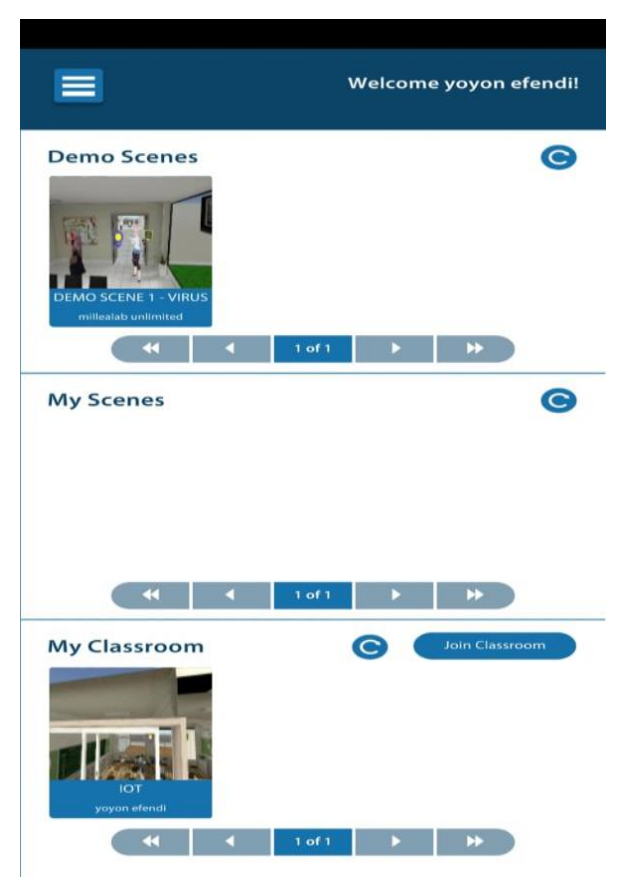

Gambar 2. Tampilan Viewer

Tampilan viewer ini akan menampilkan classroom dengan cara memasukkan kode classroom yang sudah dibagikan terlebih dahulu kepada mahasiswa. 


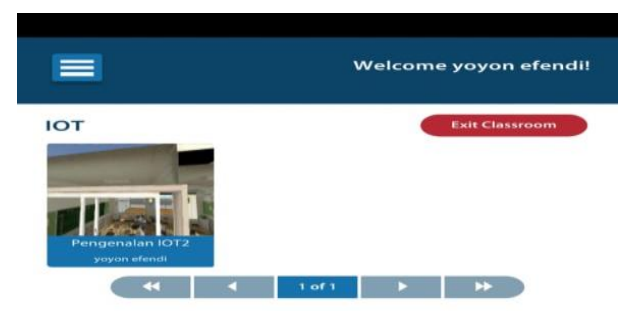

Gambar 3 Tampilan detail viewer Secara detail tampilan viewer VR dapat dilihat dengan tampilan beberapa menu untuk menjalankan aplikasi VR.

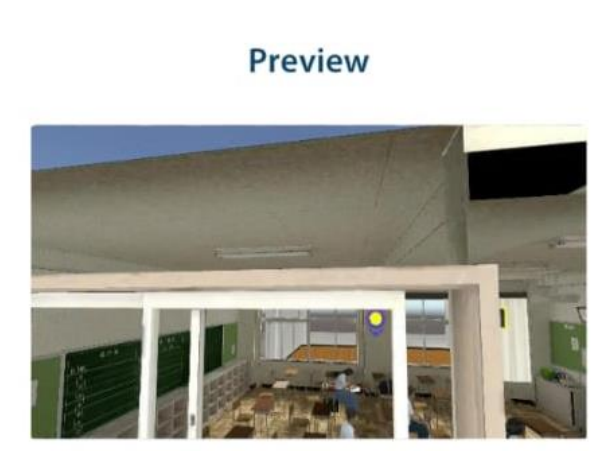

Select Mode

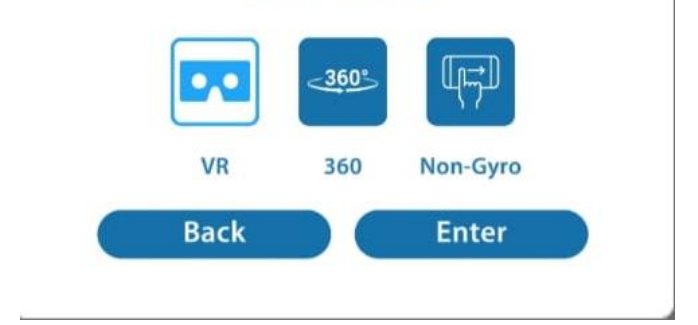

Gambar 4. Pilihan mode Viewer

Pada select mode terdapat menu 3 pilihan yaitu VR, 360 dan Non-Gyro.

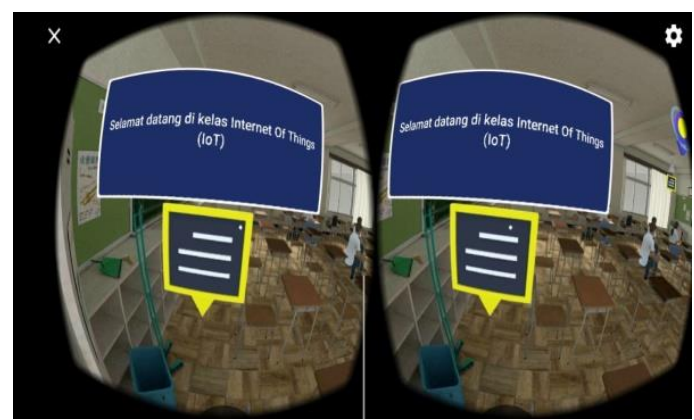

Gambar 5. Tampilan pada kelas IOT

Setelah masuk ke select mode VR dapat dilihat ucapan selamat datang dikelas Internet of things (IoT).

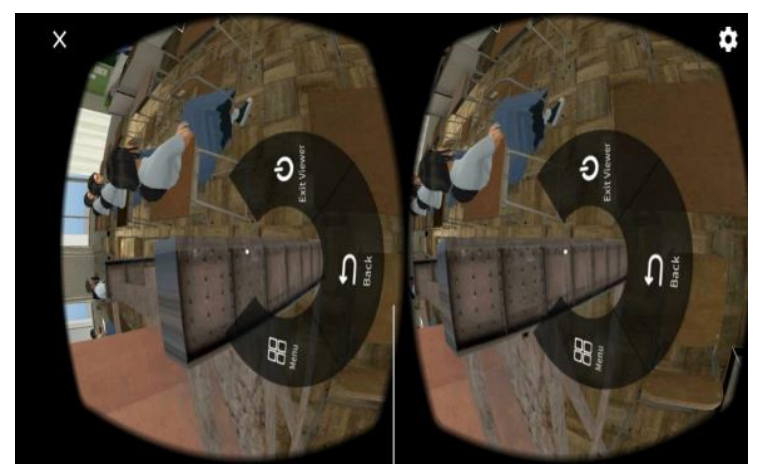

Gambar 6. Tampilan menu VR

Pada menu di aplikasi VR class terdapat menu utama, back dan keluar.

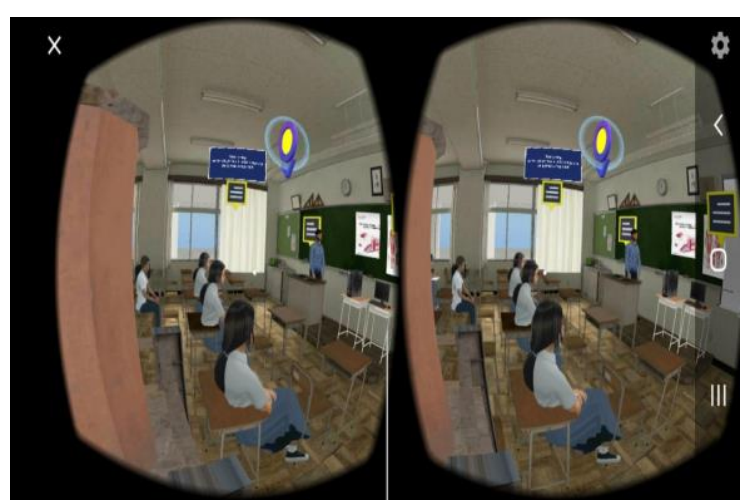

Gambar 7. Tampilan kelas VR

Pada tampilan suasana kelas VR terdapat seorang guru dan beberapa orang peserta didik. Materi bisa dilihat pada format teks dan juga video yang bisa di link youtube.

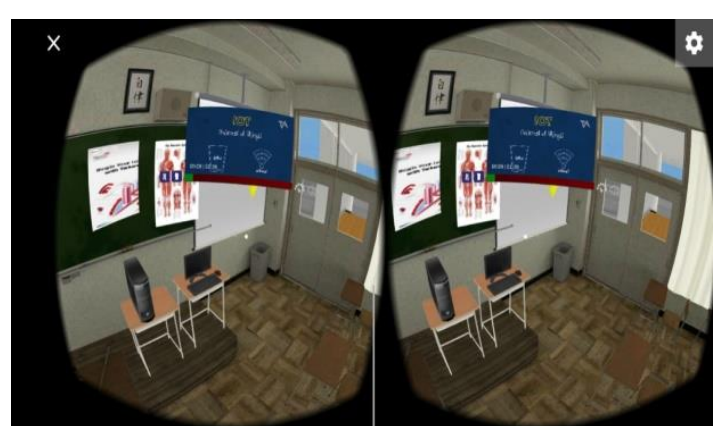

Gambar 8. Tampilan VR link video

Tampilan VR menggunakan link video dengan durasi terbatas yang dapat di ambil dari youtube.

\subsection{Pengujian}




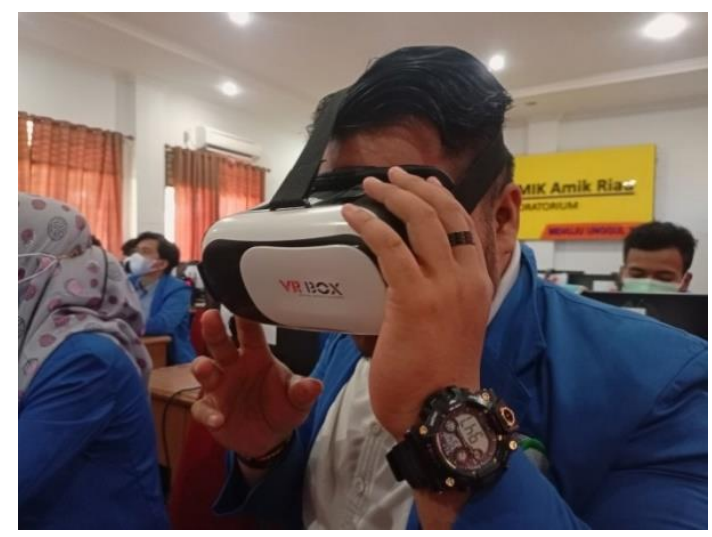

Gambar 9. Pengujian VR class

Pengujian dilakukan dilaboratorium dengan 16 orang mahasiswa prodi teknik informatika.

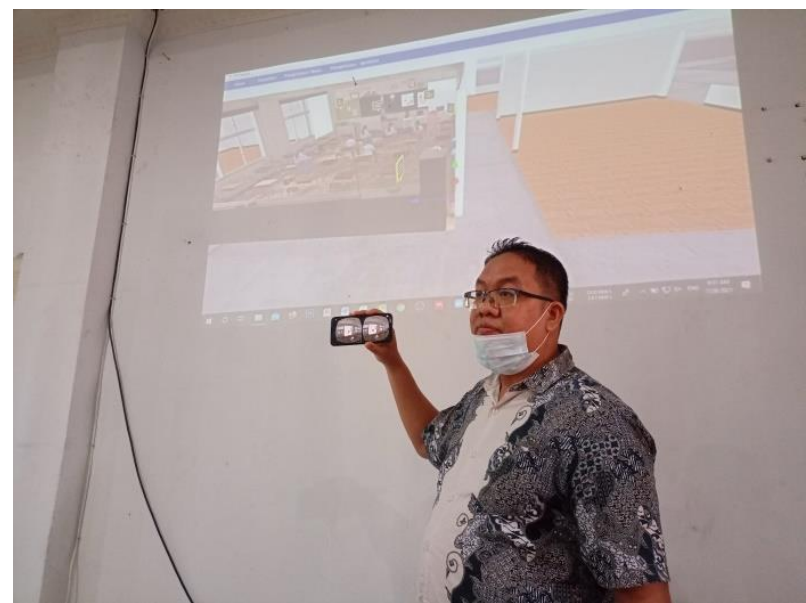

Gambar 10. Pengujian VR class Dosen

Pengujian dari VR class dilakukan oleh dosen Yoyon Efendi, M.Kom.

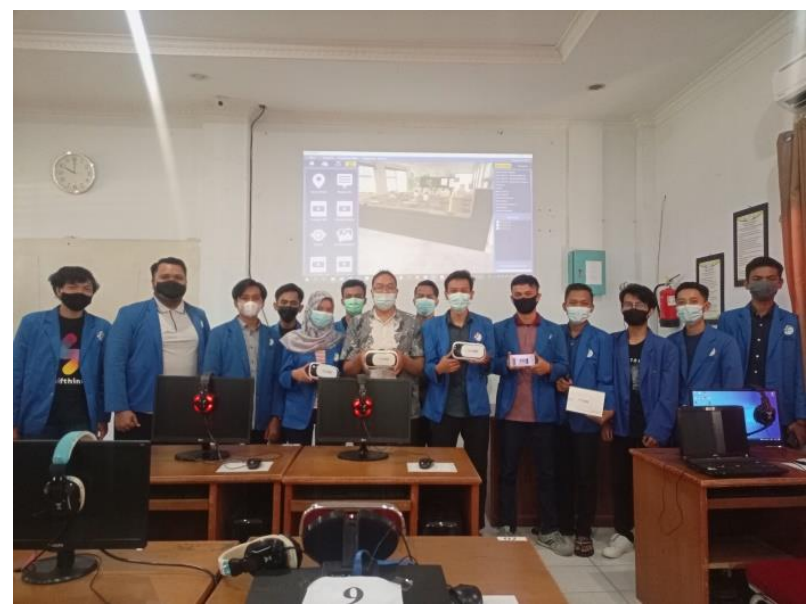

Gambar 11. Peserta pengujian VR class
Peserta pengujian VR class melakukan proses pengujian dan evaluasi VR. Berikut dibawah ini tabel 1 pengujian untuk melihat status pengujian yang dilakukan:

Tabel 1. Pengujian VR Class

\begin{tabular}{|c|l|c|}
\hline No & Nama & Hasil \\
\hline 1 & Pratama Dandi & Baik \\
\hline 2 & Nurbaita & Baik \\
\hline 3 & Risky Triadmadan & Baik \\
\hline 4 & Erik Setiawan & Baik \\
\hline 5 & Alfi Rizki & Baik \\
\hline 6 & Budi Satria N & Baik \\
\hline 7 & Zel Afriadi & Baik \\
\hline 8 & Teguh Alfalah & Baik \\
\hline 9 & Angga Pranata & Baik \\
\hline 10 & Rohmat Romadhoni & Baik \\
\hline 11 & Ari Aditama & Baik \\
\hline 12 & Alwindo Rizki & Baik \\
\hline 13 & Bambang Permadi & Baik \\
\hline 14 & Fahri Muhammad & Baik \\
\hline 15 & M Arif Bijaksana & Baik \\
\hline 16 & Abd Ghafar Tanis & Baik \\
\hline
\end{tabular}

\section{Kesimpulan}

Dari hasil pembuatan dan pengujian aplikasi VR yang telah dilaksanakan maka dapat ditarik kesimpulan sebagai berikut:

1. Hasil pengujian VR untuk kelas Internet of things berjalan dengan baik

2. 3D VR sangat membantu dosen untuk menyampaikan materi dengan baik kepada mahasiswa.

3. Dapat dikembangkan dalam materi yang lebih kompleks karena dilengkapi dengan video.

\section{UCAPAN TERIMAKASIH}

Penelitian ini dapat dilaksanakan dengan bantuan banyak pihak, untuk itu diucapkan terima kasih yang tidak terhingga kepada STMIK Amik Riau, Millaleab, Shinta VR dan Gurubinar. 


\section{Referensi}

Arifudin, A., Kuswandi, D., \& Soepriyanto, Y. (2019). Pengembangan Media Obyek 3 Dimensi Digital Sel Hewan dan Tumbuhan Memanfaatkan Piramida hologram Untuk MTS. Kajian Teknologi Pendidikan, 2(1), 9-15.

Efendi, Y., \& Junaidi, J. (2018). Aplikasi 3D Mapping Menggunakan Virtual Reality (Studi Kasus Museum Sang Nila Utama). J-SAKTI (Jurnal Sains Komputer Dan Informatika), 2(2), 107. https://doi.org/10.30645/j-sakti.v2i2.74

Gumuda, S. (2011). Dynamics of the process of changes in concentration of methane in the air of ventilation currents in mines. 2(2), 13-21.

Jamil, M. (2018). Pemanfaatan Teknologi Virtual Reality (VR) di Perpustakaan. Buletin Perpustakaan Universitas Islam Indonesia, 1(1), 99-113. https://journal.uii.ac.id/BuletinPerpustakaan/article/download/11503/86 74

Saurik, H. T. T., Purwanto, D. D., \& Hadikusuma, J. I. (2019). Teknologi
Virtual Reality untuk Media Informasi Kampus. Jurnal Teknologi Informasi Dan Ilmu Komputer, 6(1), 71. https://doi.org/10.25126/jtiik.2019611 238

Sulistyowati. (2017). Pemanfaatan Teknologi 3D Virtual Reality Pada Pembelajaran Matematika Tingkat Sekolah Dasar. Jurnal Ilmiah NERO, Volume 3(Nomor 1), Halaman 37-44.

Tafonao, T. (2018). Peranan Media Pembelajaran Dalam Meningkatkan Minat Belajar Mahasiswa. Jurnal Komunikasi Pendidikan, 2(2), 103. https://doi.org/10.32585/jkp.v2i2.113

Wahid, A. (2018). Pentingnya Media Pembelajaran dalam Meningkatkan Prestasi Belajar. Istiqra, 5(2), 1-11.

Yoyon Efendi, J. (2018). TEKNOLOGI

VIRTUAL REALITY MENGGUNAKAN SENSOR GYROSSCOPE SEBAGAI MEDIA EDUKASI BUDAYA MELAYU PADA MUSEUM. Jurnal Ilmu Komputer Dan Bisnis, 9(2), 20832091. 